\title{
Experimental Validation of a Laser Heat Source Model for Laser Melting and Laser Cladding Processes
}

\author{
W.C. Tseng and J.N. Aoh
}

\begin{abstract}
Department of Mechanical Engineering, Advanced Institute for Manufacturing with High-tech Innovations (AIM-HI), National Chung Cheng University, 168 University Road, Minhsiung, Chiayi, 621, Taiwan
\end{abstract}

\begin{abstract}
Selective laser melting (SLM) and laser cladding are laser additive manufacturing methods that have been developed for application to the near-net-shape process and 3D printing. The temperature distributions and track profiles of SLM and clad layers require additional in-depth investigation to optimize manufacturing processes. This research involved developing a tailored laser heat source model that contains a comprehensive selection of laser beam characteristics and can be used in finite element analysis of the laser melting process. This paper presents a systematic experimental validation of the applicability of the proposed laser heat source model to single-track Nd:YAG and $\mathrm{CO}_{2}$ laser melting simulations. The evolution of the melt pool isotherms and the variation in track profiles caused by adjusting the laser power and scanning speed were numerically predicted and experimentally verified. Appropriate process parameters and the threshold power for continuous track layer formation were determined. The balling phenomenon on preplaced powder was observed at power levels below the threshold values. Nd:YAG laser melting resulted in a wide and shallow track profile, which was adequately predicted using the numerical simulation. $\mathrm{CO}_{2}$ laser melting resulted in a triangular track profile, which deviated slightly from the finite element prediction. The results indicated a high level of consistency between the experimental and the numerical results regarding track depth evolution, whereas the numerically predicted track width evolution deviated slightly from the experimentally determined track width evolution. This parametric laser melting study validated the applicability of the proposed laser heat source model in numerical analysis of laser melting processes such as SLM and laser cladding.
\end{abstract}

Keywords: Finite element analysis, laser cladding, laser heat source model, melt pool, preplaced powder, selective laser melting (SLM), track profile.

\section{INTRODUCTION}

Selective laser sintering (SLS) and selective laser melting (SLM) are emerging methods used for rapid prototyping in the laser additive manufacturing (LAM) process [1, 2]. These methods share an operational concept with the laser cladding process. Melting and consolidation of a thin powder layer during these processes are achieved by scanning a laser beam over a thin powder layer that is deposited on a previously solidified powder layer or over a preplaced powder layer on a substrate. The thin powder layers are consecutively fused to the underlying substrate to form an additive bulk workpiece. The main differences between SLM and laser cladding lie in the dimensions of the tracked profile and in the required laser power range. Typically the thickness of the molten track for SLM is in the order of several hundred microns, whereas the clad layer thickness may range from several hundred microns to $1-2 \mathrm{~mm}[3,4]$. To melt the powder and substrate, SLM requires a laser power of several watts, whereas the laser cladding process requires several hundred to one thousand watts $[3,5]$. Another common requirement for these two laser melting

*Address correspondence to this author at the Department of Mechanical Engineering, Advanced Institute for Manufacturing with High-tech Innovations (AIM-HI), National Chung Cheng University, 168 University Road, Minhsiung, Chiayi, 621, Taiwan; Tel: 8865 2721429;

Fax: 8865 2720589; E-mail: imejna@ccu.edu.tw processes is that low dilution between the molten track and the underlying solid substrate must be maintained to guarantee efficient layer forming and sufficient mechanical strength or hardness of the workpiece [3].

Both the analytical and numerical aspects of the temperature distribution and molten track profile during laser rapid manufacturing and laser cladding using direct powder feeding have been studied [6-11]. Zhang et al. conducted a thermomechanical analysis and an experiment on multi-bead laser powder deposition (LPD) [6]. Alimardani et al. [7] investigated the effect of dynamic preheating on direct powder feeding laser cladding. Fathi et al. [8] presented an analytical model of LPD using a moving point heat source to predict the temperature field, melt pool depth, and dilution and validated the predictions experimentally. Kumar et al. [9] developed analytical approaches for predicting the clad geometry of the direct powder feeding technique in which surface tension and the convection of the melt pool were considered. Kumar et al. [10] simulated the temperature distribution and single-track geometry in the direct powder feeding in LAM of metal structures by using a twodimensional finite element model (FEM).

Compared with the direct powder feeding technique, laser cladding using the preplaced powder layer technique is simple and efficient and is the most suitable technique for fabricating workpieces with large-area protective coatings or 
workpieces with a complex geometry to improve the corrosion and wear resistance [1,12]. Although few analytical and numerical investigations have addressed the temperature and melt pool evolution during laser cladding with a preplaced powder process $[13,14]$, increasing interest has focused on research involving theoretical and numerical modeling of the SLM process with a preplaced powder bed; this process is similar to the laser cladding process with a preplaced powder layer. Studies on the theoretical and numerical modeling of the SLM process and laser cladding process with preplaced powder have made it possible to improve predictions of the deposition of the clad layer or additive layers during the laser melting process and to optimize process parameters [5,10,15,17-23]. Most of the existing techniques for modeling SLS, SLM, and laser cladding $[9,11,13,14,15]$ have focused on Gaussian heat source models. These heat source models are oversimplified and cannot accurately describe the characteristics of laser beams; therefore, these models do not enable precise theoretical or numerical analyses. For example, the double ellipsoidal heat source model [24] was mainly developed to facilitate simulation of arc welding processes; however, it was also applied in analyzing the additive manufacturing process [25]. Few studies [26] have investigated the effect of the fundamental laser beam modes, $\mathrm{TEM}_{00}$ and $\mathrm{TEM}_{01}$, on the melt pool profile. However, laser melting processes, such as SLM and the laser cladding process, may require a defocused beam and a beam featuring a tailored-shaped energy distribution profile of higher TEM modes or multimode. Therefore, a laser beam model that considers a comprehensive selection of the physical characteristics of a laser beam is highly relevant to a precise simulation of laser melting processes such as SLM and laser cladding in the same way as it is imperative to consider arc physics in arc welding modeling [27]. The aforementioned laser beam models either exhibited limitations [28] or were not appropriate for SLM and laser cladding. The authors of this paper previously proposed a novel laser heat source model tailored to laser heating and melting that considers a comprehensive selection of laser beam characteristics. A numerical simulation of a laser melting process with a preplaced cobalt powder layer was conducted to predict the evolution of melt pool isotherms and the clad bead profiles based on limited preliminary experimental evidence [29]. This study involved conducting a systematic laser melting experiment to investigate the consistency between the experimental result produced by a Nd:YAG laser and a $\mathrm{CO}_{2}$ laser and numerical predictions of laser melting of a preplaced powder layer based on the proposed laser heat source model. The objective of this research was to provide convincing experimental data to validate the feasibility and applicability of the tailored laser heat source model in the numerical analysis of laser melting and the laser cladding process. In addition, the results of the experimental validation and the numerical model improve the knowledge base for an in-depth understanding of the temperature and melt pool evolution during laser melting processes including laser cladding in laser surface modification and SLM in LAM.

\section{MATHEMATICAL FORMULATION OF THE TAILORED LASER HEAT SOURCE}

Fig. (1) schematically depicts a tailored TEM mixed $_{\text {mode }}$ laser beam emerging from a focusing lens with focal length $f$ and its projection on a workpiece surface at a defocus distance $a$ from the focal point. The radius of the laser spot projected on the surface of the workpiece is $r_{w}$. The radius of the raw beam that emerges from the focusing lens (or mirror) is $r_{0}$. The spot radius at the focal point is $r_{f}$. The relationship between $r_{f}$ and the focal length $f$ is

$$
r_{f}=\frac{f \cdot \theta}{2}=\frac{\lambda \cdot f}{\pi \cdot r_{0}}
$$

where $\theta=\frac{4 \lambda}{\pi \cdot 2 r_{0}}$ is the divergence angle and $\lambda$ is the wavelength of the selected laser.

The heat flux distribution of the laser beam to which the workpiece is exposed is formulated by considering the laser intensity distributions of a $\mathrm{TEM}_{00}$ mode and a $\mathrm{TEM}_{m n}$ mode. The heat flux distribution of a $\mathrm{TEM}_{00}$ mode laser beam, $q_{0}$, can be expressed as

$$
q_{0}(r)=q_{\text {omax }} \exp \left(-k_{0} r^{2}\right)
$$

where $r=\left(x^{2}+y^{2}\right)^{1 / 2} ; q_{0 \max }$ is the maximum heat flux; and $k_{0}$ is the concentration coefficient.

Assume that no power is lost at the focusing lens. The laser power $Q_{0}$ at the focusing lens can be derived as

$Q_{0}=\frac{q_{0 \max } k_{0}}{\pi}$

Therefore,

$$
q_{0}(r)=\frac{Q_{0} k_{0}}{\pi} \exp \left(-k_{0} r^{2}\right)
$$

In accordance with [33], $q_{0}(r)=0.05 q_{0 \max }$ at $r=r_{0}$. Thus, the relationship between the concentration coefficient $K_{0}$ and the raw beam radius $r_{0}$ is $k_{0}=\frac{3}{r_{0}^{2}}$; therefore,

$$
q_{0}(r)=\frac{3 Q_{0}}{\pi r_{0}^{2}} \exp \left(-\frac{3 r^{2}}{r_{0}^{2}}\right)
$$

Assume that no energy loss occurs between the focusing lens and the focal point. The heat flux intensity of a TEM laser beam at the focal point is

$$
q_{f}(r)=\frac{3 Q_{0} \pi r_{0}^{2}}{\lambda^{2} f^{2}} \exp \left(-\frac{3 r^{2}}{r_{0}^{2}}\right)
$$

The radius of the beam on the workpiece $r_{w}$ at any arbitrary position that is $a$ from the focal point is approximately expressed as

$$
r_{w}=\frac{f \cdot r_{f}+a \cdot\left(r_{0}-r_{f}\right)}{f}
$$

The heat flux distribution $q_{m n}$ of a $\mathrm{TEM}_{m n}$ mode raw laser beam is defined as 


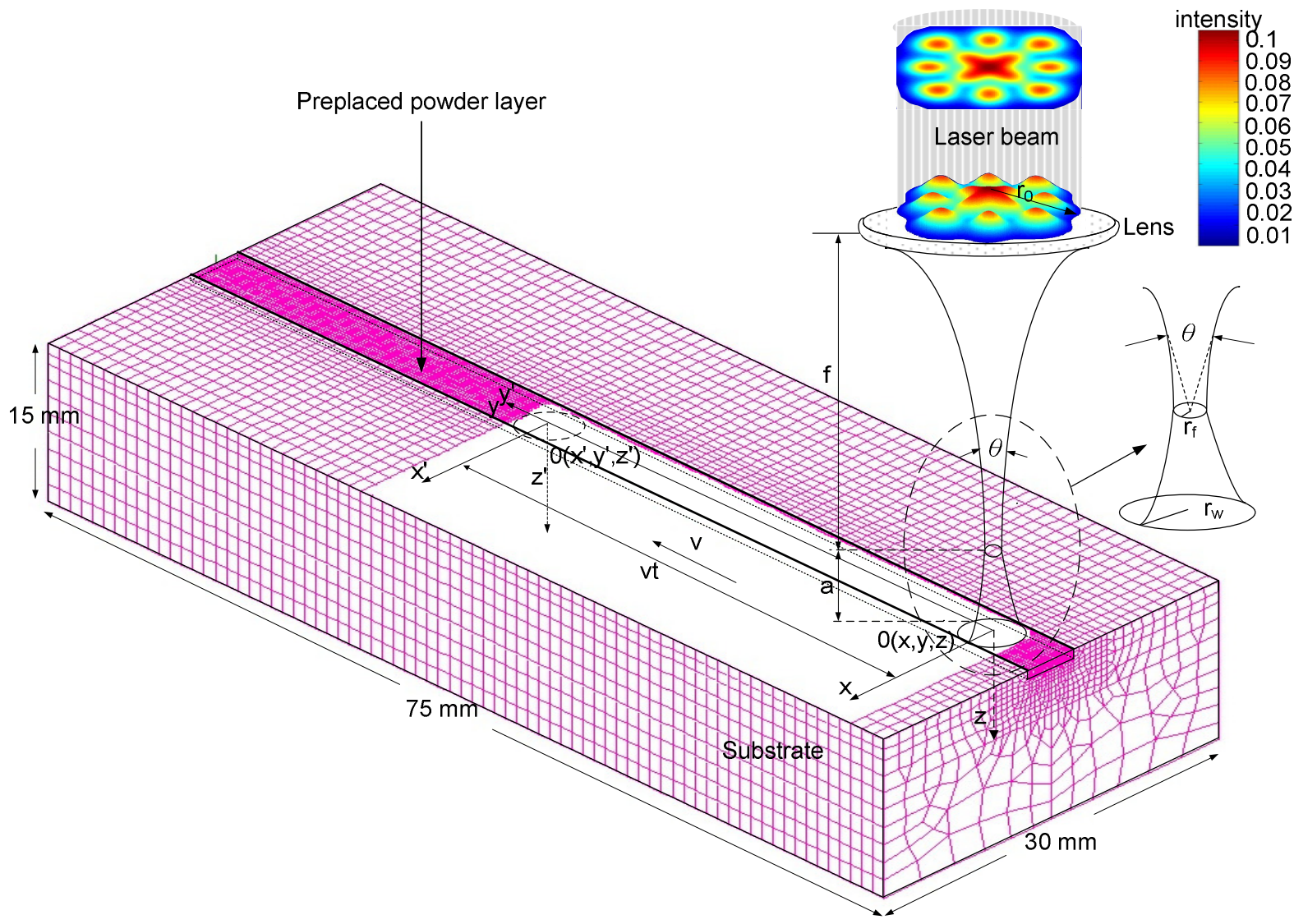

Fig. (1). Schematic illustration of a tailored $\mathrm{TEM}_{\text {mixed }}$ mode laser heat source model moving along a preplaced powder layer on a meshed substrate during selective laser melting.

$q_{m n}(x, y)=\frac{1}{2^{m+n} m ! n !} \frac{1}{r_{0}^{2}} H_{m}^{2}\left(\frac{\sqrt{2} x}{r_{0}}\right) H_{n}^{2}\left(\frac{\sqrt{2} y}{r_{0}}\right) \exp \left(-2 \frac{\left(x^{2}+y^{2}\right)}{r_{0}^{2}}\right)$

where $H_{m}$ and $H_{n}$ are Hermite polynomials of orders $m$ and $n$, respectively. The total power $Q_{m n}$ of the $\mathrm{TEM}_{m n}$ mode raw beam is

$Q_{m n}=\pi \cdot r_{0}^{2} \cdot q_{m n}(x, y)$

Assume that no energy loss occurs, and $Q_{m n}=Q_{f}=Q_{w}$, where $Q_{f}$ is the power at the focusing point and $Q_{w}$ is the power at an arbitrary position that is $a$ from the focal point

$q_{f}(x, y)=\left(\frac{\pi \cdot r_{0}}{f \cdot \lambda}\right)^{2} \frac{1}{2^{m+n} m ! n !} H_{m}^{2}\left(\frac{\sqrt{2} x}{r_{0}}\right) H_{n}^{2}\left(\frac{\sqrt{2} y}{r_{0}}\right) \exp \left(-2 \frac{\left(x^{2}+y^{2}\right)}{r_{0}^{2}}\right)$

Similarly, the heat flux distribution of a $\mathrm{TEM}_{m n}$ mode laser beam at an arbitrary focusing position $a$ can be expressed as

$q_{w}(x, y)=\left(\frac{r_{0}}{r_{w}}\right)^{2} \frac{1}{2^{m+n} m ! n !} \frac{1}{r_{0}^{2}} H_{m}^{2}\left(\frac{\sqrt{2} x}{r_{0}}\right) H_{n}^{2}\left(\frac{\sqrt{2} y}{r_{0}}\right) \exp \left(-2 \frac{\left(x^{2}+y^{2}\right)}{r_{0}^{2}}\right)$

These equations explicitly express the heat flux that is determined using the proposed laser heat source model in terms of beam mode, power, wavelength, beam radius, focal length of focusing optics, and defocusing conditions.

The tailored heat flux distribution of a multiple mode laser beam $\mathrm{TEM}_{\text {mixed }}$ is defined as $q_{\text {mixed }}$ and can be determined by superimposing the heat flux distribution of the individual $\mathrm{TEM}_{m n}$ modes that constitute the mixed mode. Each individual mode shares a fraction $a_{i}$ of the total heat flux [9]. Thus, $q_{\text {mixed }}$ can be expressed generally as $q_{\text {mixed }}=\sum_{i=1}^{n} a_{i} \cdot q_{f}$, where $\sum_{i=1}^{n} a_{i}=1$. The $\mathrm{TEM}_{\text {mixed }}$ mode is composed of $\mathrm{TEM}_{00}, \mathrm{TEM}_{01}, \mathrm{TEM}_{10}, \mathrm{TEM}_{11}$, and $\mathrm{TEM}_{33}$ modes. The heat flux of the mixed mode of Nd:YAG lasers can be expressed as (12), and that of $\mathrm{CO}_{2}$ lasers can be expressed as (13). The heat fluxes of these lasers are illustrated in Fig. (2a) and Fig. (2b), respectively.

$$
\begin{aligned}
& q_{\text {mixed }}=0.1 q_{00}+0.15 q_{01}+0.15 q_{10}+0.3 q_{11}+0.3 q_{33} \\
& q_{\text {mixed }}=0.5 q_{00}+0.15 q_{01}+0.15 q_{10}+0.1 q_{11}+0.1 q_{33}
\end{aligned}
$$

The individual modes used to compose a tailored $\mathrm{TEM}_{\text {mixed }}$ mode were selected empirically. The purpose was to generate a multimode raw laser beam that could be employed in numerical simulation and featured an intensity distribution close to that of a multimode $\mathrm{Nd}: \mathrm{YAG} / \mathrm{CO}_{2}$ raw laser beam used in laser melting. The Nd:YAG laser beam 


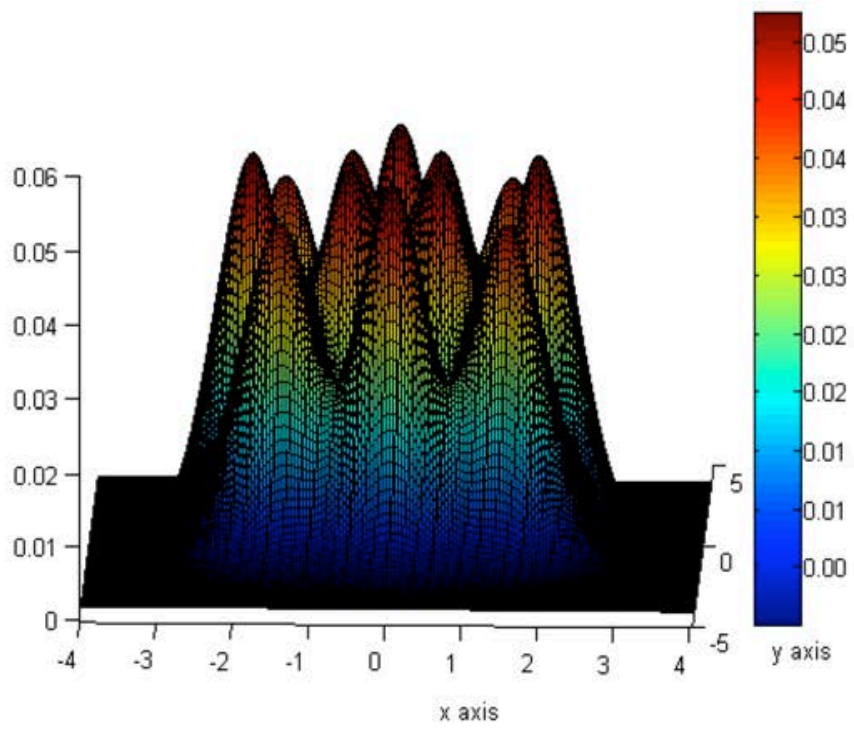

(a) Nd:YAG laser

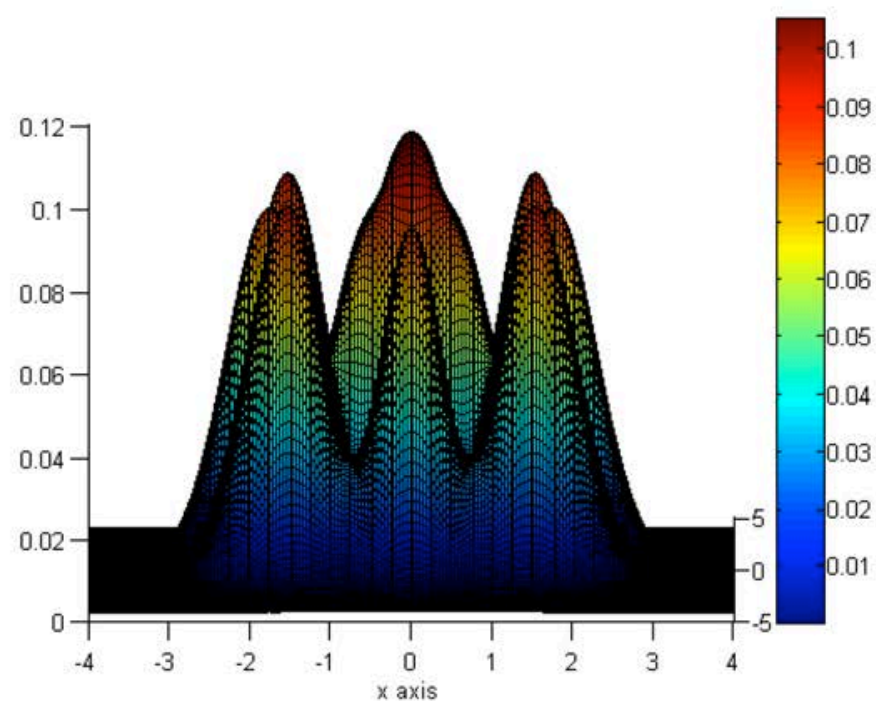

(b) $\mathrm{CO}_{2}$ laser

Fig. (2). Intensity distribution of the tailored $\mathrm{TEM}_{m i x e d}$ mode laser heat sources consisting of TEM $\mathrm{TE}_{00}, \mathrm{TEM}_{01}, \mathrm{TEM}_{10}, \mathrm{TEM}_{11}, \mathrm{TEM}_{33} \mathrm{modes}$

profile was measured using a profile power meter at the exit of the laser cavity; however, the heat flux intensity distribution of a $\mathrm{CO}_{2}$ laser beam is normally determined in practice by impinging a raw laser beam onto an acrylic plate to form a burnt crater. Normalized to a unit intensity distribution of the $\mathrm{TEM}_{00}$ mode Gaussian beam, the peak intensity of the Nd:YAG laser beam given by (12) and the peak intensity of the $\mathrm{CO}_{2}$ laser beam described by (13) are approximately 0.05 and 0.1 , respectively.

Consider a reference frame that is fixed relative to the laser heat source that moves in the y direction of a Eulerian coordinate system at a constant speed $v$ with respect to the reference frame, where $x^{\prime}=x, y^{\prime}=y$ - vt', and $z^{\prime}=z$. The temperature field resulted from a $\mathrm{TEM}_{m n}$ mode laser is expressed as

$$
\begin{aligned}
& T(x, y, z, t) \\
& =\frac{\eta}{k \alpha^{1 / 2}(4 \pi t)^{3 / 2}} \int_{0}^{t} \int_{-\infty}^{\infty} \int_{-\infty}^{\infty} \int_{-\infty}^{\infty} q\left(x^{\prime}, y^{\prime}\right) \cdot e^{-\frac{x^{\prime 2}+\left(y-v t^{\prime}\right)^{2}+z^{2}}{4 \alpha t}} d t^{\prime} d x^{\prime} d y^{\prime} d z^{\prime} \\
& +\frac{1}{(4 \pi \alpha t)^{3 / 2}} \int_{-\infty}^{\infty} \int_{-\infty}^{\infty} \int_{-\infty}^{\infty} A\left(x^{\prime}, y^{\prime}, z^{\prime}\right) \cdot e^{-\frac{x^{\prime 2}+\left(y-v t^{\prime}\right)^{2}+z^{2}}{4 \alpha t}} d t^{\prime} d x^{\prime} d y^{\prime} d z^{\prime}
\end{aligned}
$$

where $q\left(x^{\prime}, y^{\prime}\right)$ is given by (10) and (11). $A\left(x^{\prime}, y^{\prime}, z^{\prime}\right)$ is the initial temperature, $v$ is the scanning speed, and $\alpha$ is the thermal diffusivity. Equation (14) expresses the transient temperature profile of the powder layer and the substrate; this profile is determined by using the proposed laser heat source model as a moving heat source scanning over the workpiece.

\section{EXPERIMENTAL DETAILS AND NUMERICAL MODELING}

A Rofin CW025 Nd:YAG laser and a Rofin DC035 $\mathrm{CO}_{2}$ laser were used to perform single-pass laser melting and laser cladding. The multimode Nd:YAG laser beam $(\lambda=$ $1.063 \mu \mathrm{m}$ ) had a raw beam radius of $19 \mathrm{~mm}$ and was focused using a lens with a focal length of $120 \mathrm{~mm}$ to a beam radius of $0.2 \mathrm{~mm}$. The multimode $\mathrm{CO}_{2}$ laser beam $(\lambda=10.63 \mu \mathrm{m})$ had a raw beam radius of $16 \mathrm{~mm}$ and was reflected onto the specimens by using a copper mirror with a focal length of $250 \mathrm{~mm}$. The power of the $\mathrm{CO}_{2}$ laser was varied from $600 \mathrm{~W}$ to $2000 \mathrm{~W}$, and that of the Nd:YAG laser was varied from $1500 \mathrm{~W}$ to $3000 \mathrm{~W}$. The scanning speed of the laser beam was varied from $100 \mathrm{~mm} / \mathrm{min}$ to $400 \mathrm{~mm} / \mathrm{min}$. A laser melt track of $75 \mathrm{~mm}$ in length was completed in $37.5 \mathrm{~s}$ at a scanning speed of $120 \mathrm{~mm} / \mathrm{min}$. A laser power of $2000 \mathrm{~W}$ and a scanning speed of $120 \mathrm{~mm} / \mathrm{min}$ were employed, unless other values are specified. Argon was used as the protective gas and the assist gas in the experiment. The flow rate of the assist gas was $10 \mathrm{l} / \mathrm{min}$. Backward purging of the assist gas was crucial to laser cladding and laser melting to ensure smooth track formation and a uniform track profile. A preplaced Cobalt-based Stellite 6 alloy powder layer was uniformly deposited on an S45C medium carbon steel plate in paste form. When it had dried, an approximately $1.5-\mathrm{mm}-$ thick preplaced powder layer was adhered to the substrate. After laser melting, the solidified track became considerably thinner than the preplaced layer.

The FEM of the preplaced layer and the substrate (Fig. 1) had dimensions of $75 \mathrm{~mm}(\mathrm{~L}) \times 30 \mathrm{~mm}(\mathrm{~W}) \times 15 \mathrm{~mm}(\mathrm{H})$ and was meshed into 54494 elements and 48944 nodes. The width of the preplaced layer was set as $2 \mathrm{~mm}$ and the depth was set as $0.3 \mathrm{~mm}$. In general, the melt depth was not allowed to exceed twice the depth of the preplaced layer to ensure that dilution remained lower than $50 \%$ during the laser melting process [30]. The grid-mesh model and material properties were detailed in [29]. The heat convection coefficient from the workpiece to the surrounding environment was $25 \mathrm{~W} / \mathrm{mm}^{2} \mathrm{~K}$. The initial temperature on the surface of the workpiece was $25^{\circ} \mathrm{C}$. 


\section{EXPERIMENTAL RESULTS VERSUS NUME- RICAL PREDICTIONS}

\subsection{Effect of Laser Power on the Temperature Distri- bution and track Profile}

Fig. (3) shows the numerical prediction of the effect of the Nd:YAG laser power on the transient melt track profile (or melt pool contour) and the temperature distribution of the melt pool during laser melting on a preplaced powder layer. The melting track profile (or the melt pool contour) was determined by setting the temperature scale in Figs. $(\mathbf{3}, \mathbf{4})$ from $30{ }^{\circ} \mathrm{C}$ to the melting temperature of the cobalt alloy, $1350{ }^{\circ} \mathrm{C}$. The area where the temperature exceeded $1350{ }^{\circ} \mathrm{C}$ was regarded as the melt pool. When the Nd:YAG laser was applied, the melt pool formed when the laser power exceeded 2000 W, as shown in Fig. (3b). The solidified track reached a desired width of $2 \mathrm{~mm}$ at a laser power greater than $2500 \mathrm{~W}$, as shown in Fig. (3c). The track width and depth increased approximately linearly as the laser power was increased. To ensure efficient additive deposition as well as low dilution of the melt pool with the underlying substrate, a wide and shallow track profile must be employed. Excessively high power caused the track profile to contract and deepen; these characteristics are not desirable for the purpose of laser melting and cladding.

The evolution of the calculated solidified track profile for the $\mathrm{CO}_{2}$ laser is illustrated in Fig. (4). The melt pool formed at a power greater than $2000 \mathrm{~W}$ when the Nd:YAG laser was applied, and the predicted power required for the formation of deposited track was $600 \mathrm{~W}$ for the $\mathrm{CO}_{2}$ laser, as shown in
Fig. (4a). The track width reached an expected value of 2 $\mathrm{mm}$ in the power range between $800 \mathrm{~W}$ and $1000 \mathrm{~W}$, as shown in Fig. (4b, c). Compared with the Nd:YAG laser, substantially less power was required for the $\mathrm{CO}_{2}$ laser to form a melt pool and to achieve a track profile with the desired width. This result was attributed to the physical characteristics of the $\mathrm{CO}_{2}$ laser beam, such as the wavelength, beam waist, spot size, and power density, considered in the tailored heat source model. Although both the track width and depth increased linearly as the $\mathrm{CO}_{2}$ laser power was increased, the melt depth increased more rapidly as the $\mathrm{CO}_{2}$ laser power was increased beyond $2000 \mathrm{~W}$, as shown in Fig. (4c, d). This result indicated that the track profile contracted and deepened, thus becoming less desirable. In addition, the calculated peak temperature in the melt pool ranged from $1235{ }^{\circ} \mathrm{C}$ to $2630{ }^{\circ} \mathrm{C}$ when the $\mathrm{Nd}$ :YAG laser was applied and from $1619{ }^{\circ} \mathrm{C}$ to $5833{ }^{\circ} \mathrm{C}$ when the $\mathrm{CO}_{2}$ laser was employed. The $\mathrm{CO}_{2}$ laser evidently exhibited a higher efficiency in heating the materials than did the Nd:YAG laser, even at lower power levels.

Fig. (5) shows the surface morphology of the track formed from the preplaced powder layer at various power levels applied in experimental laser melting conducted using the Nd:YAG and the $\mathrm{CO}_{2}$ lasers. The power required for the $\mathrm{Nd}$ :YAG laser to form a uniform track was greater than 2000 $\mathrm{W}$, as shown in Fig. (5a). To achieve a uniform deposited track or clad bead, the laser power was required to be high enough to melt the preplaced powder and the surface of the underlying substrate. Applying a power lower than $500 \mathrm{~W}$ resulted in the loss of powder because the assist gas was

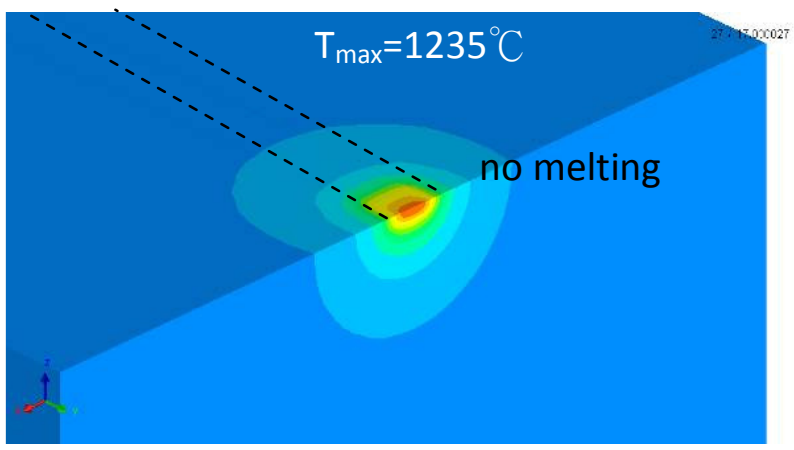

(a) Laser power: $1500 \mathrm{~W}$

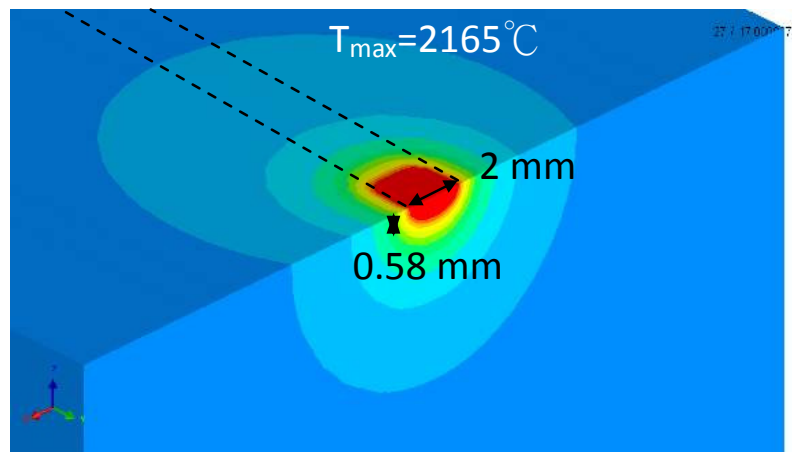

(c) Laser power: $2500 \mathrm{~W}$

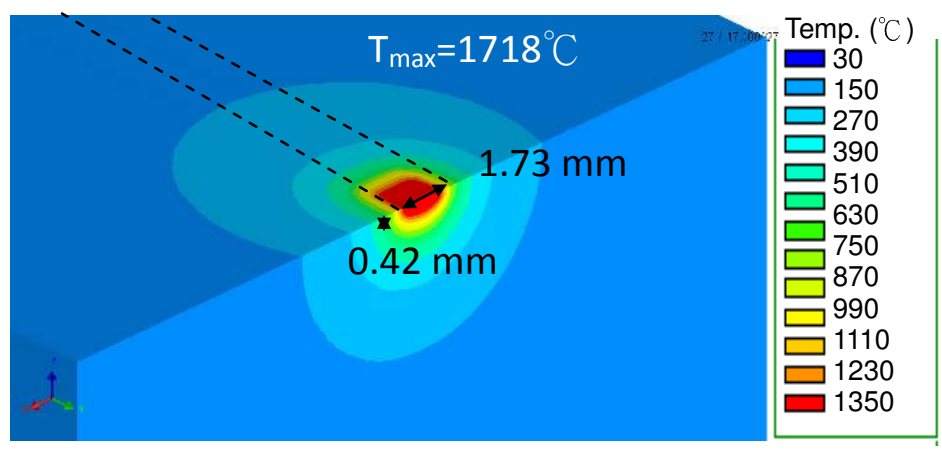

(b) Laser power: $2000 \mathrm{~W}$

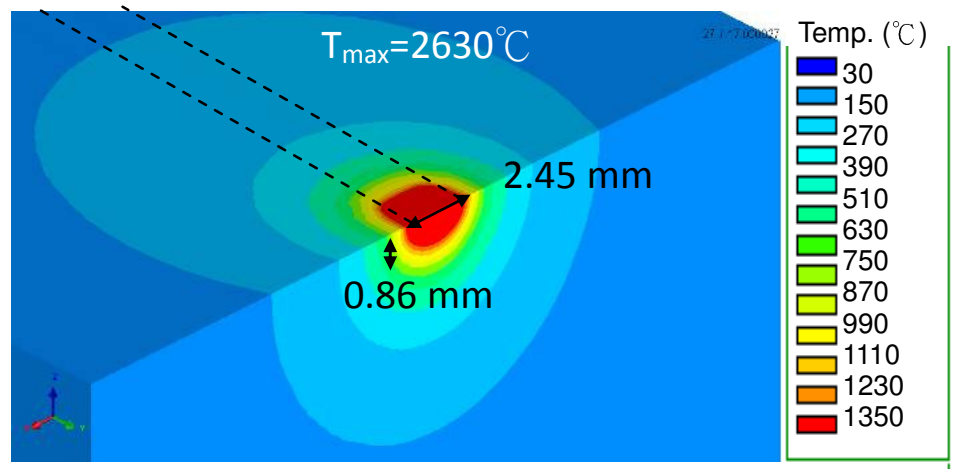

(d) Laser power: $3000 \mathrm{~W}$

Fig. (3). Effect of Nd:YAG laser power on the transient melt pool contour and the temperature distribution during laser melting on a preplaced powder layer at $\mathrm{t}=20 \mathrm{~s}$. Scanning speed: $120 \mathrm{~mm} / \mathrm{min}$, focal point: $9 \mathrm{~mm}$ above surface. 


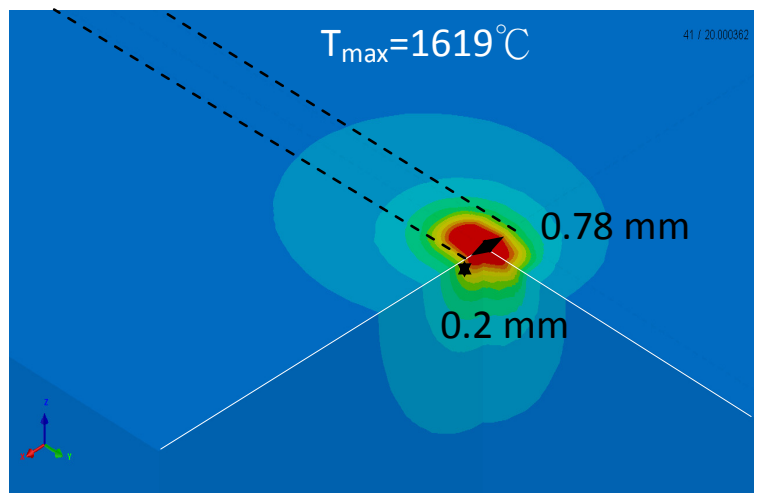

(a) Laser power: $600 \mathrm{~W}$

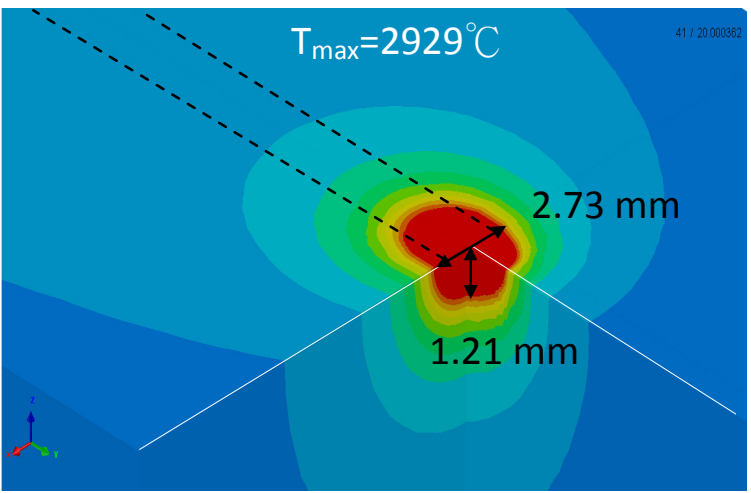

(c) Laser power: $1000 \mathrm{~W}$

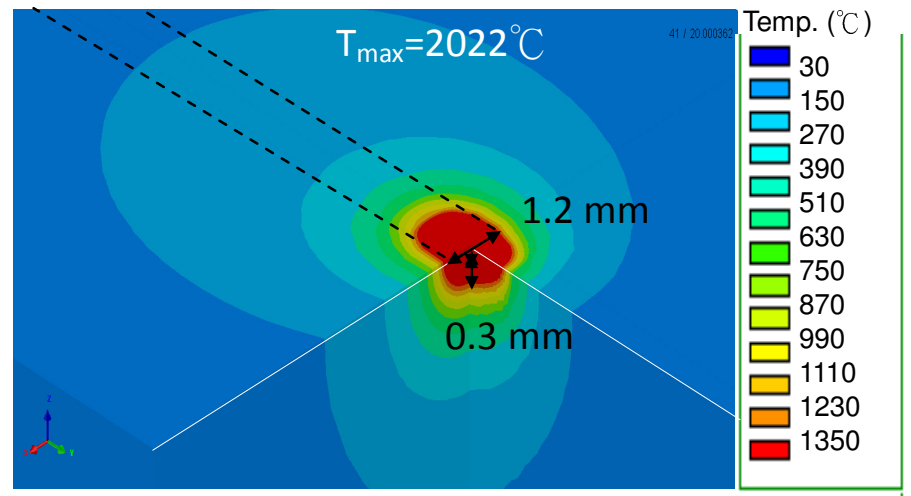

(b) Laser power: $800 \mathrm{~W}$

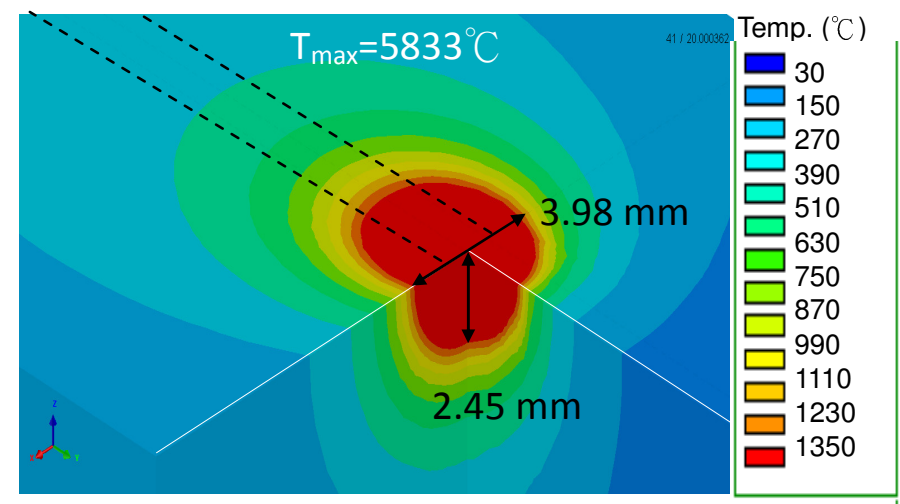

(d) Laser power: $2000 \mathrm{~W}$

Fig. (4). Effect of $\mathrm{CO}_{2}$ laser power on the transient melt pool contour and the temperature distribution during laser melting on a preplaced powder layer at $\mathrm{t}=20 \mathrm{~s}$. Scanning speed: $120 \mathrm{~mm} / \mathrm{min}$, focal point: $9 \mathrm{~mm}$ above surface.

purged. The insufficient laser power of $1000 \mathrm{~W}$ resulted in the formation of a discontinuous track along the laser scanning direction as well as the distribution of irregular beads or droplets along the track. This resembled the "balling phenomenon" frequently observed in the SLM process on solidified tracks less than $1 \mathrm{~mm}$ in diameter $[4,16,18,25,31]$. The balling phenomenon could be reduced or eliminated by adjusting the process parameters to an appropriate range and by using a two-component powder [16]. The surface morphology and the surface roughness of the solidified track in the case of laser cladding depended on the assist purge gas and the powder binder, which may have influenced the surface tension of the melt pool and the wetting between the alloy powder and the substrate. These experimental results provide a parametric basis for SLM of a powder bed. In addition to introducing a tailored laser heat source model into finite element modeling, a more precise and realistic numerical simulation of the wetting phenomena of the powder and the surface profile of the solidified track requires considering the surface tension and capillary effect in the material model [16].

The numerical prediction on laser melting using Nd:YAG laser at $2000 \mathrm{~W}$ shown in Fig. (3b) was consistent with the experimental results at the same power level depicted in Fig. (5). In contrast to Fig. (5a), Fig. (5b) shows that the $\mathrm{CO}_{2}$ laser achieved continuous and uniform melt track in the observed power range. The track width increased as the power was increased. The calculated results regarding melt pool formation in Fig. (4) depict a trend consistent with the experimental results depicted in Fig. (5b).

Figs. $(6,7)$ show the effect of the laser power on a transverse section of solidified track. For the Nd:YAG laser, the threshold power for the track formation was $1800 \mathrm{~W}$. A thin deposition layer with a concave track shape formed on the substrate, as shown in Fig. (6b). At high power levels, namely $2500 \mathrm{~W}$ and $3000 \mathrm{~W}$, the tracks were wide and shallow. One study observed an irregularly shaped transverse profile exhibiting a spike-like boundary with the substrate in laser cladding [11]. Fissures in the solidified bead have also been observed. When the $\mathrm{CO}_{2}$ laser was applied, a thin deposition layer with a slight concave track profile formed at a threshold power of $800 \mathrm{~W}$, as shown in Fig. (7a). By further increasing the laser power to $1500 \mathrm{~W}$ and $2500 \mathrm{~W}$, stable melting of the substrate and the formation of a continuous and uniform track was achieved. However, the transverse track profile exhibited a triangular shape similar to a laser weld profile. Because the melt depth increased rapidly as the power of the $\mathrm{CO}_{2}$ laser was increased beyond $1500 \mathrm{~W}$, the underlying deposited tracks or underlying substrate melted too much; this result is undesirable for additive deposition. A similar triangular track profile was observed in single-track SLM of SS316 powder on a steel substrate performed using a $\mathrm{Yb}$-fiber laser [32]. 


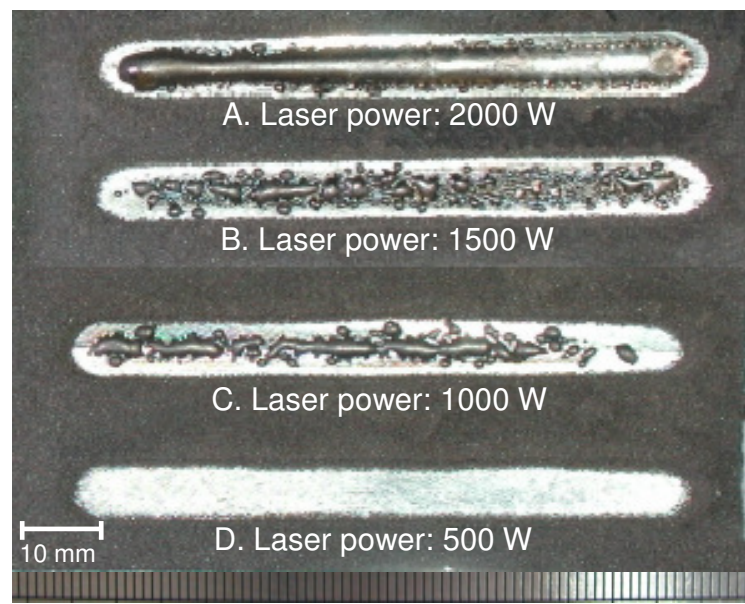

(a) $\mathrm{Nd}$ :YAG laser

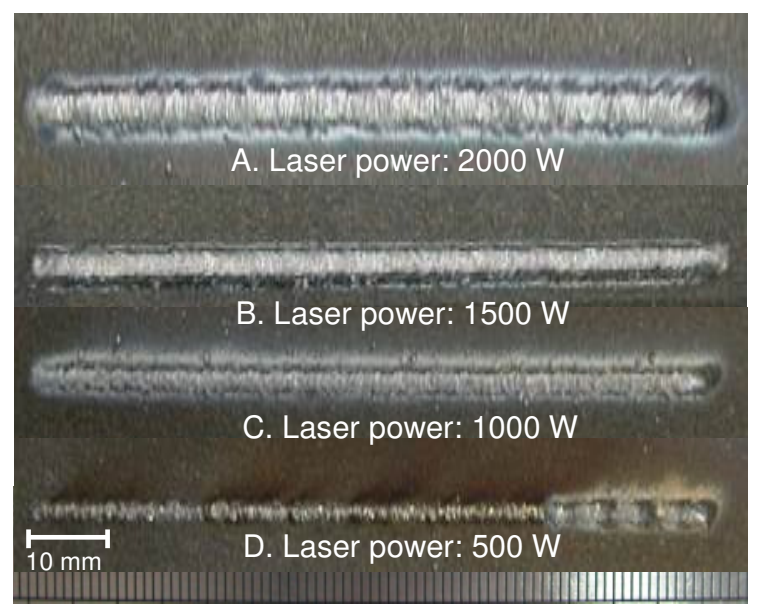

(b) $\mathrm{CO}_{2}$ laser

Fig. (5). The surface morphology of the selective melting track solidified from a preplaced powder layer at various power levels.

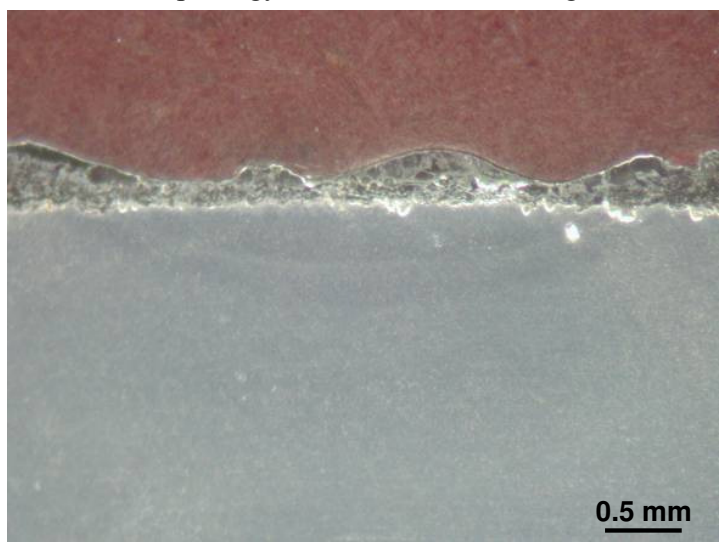

(a) Laser power: $1400 \mathrm{~W}$

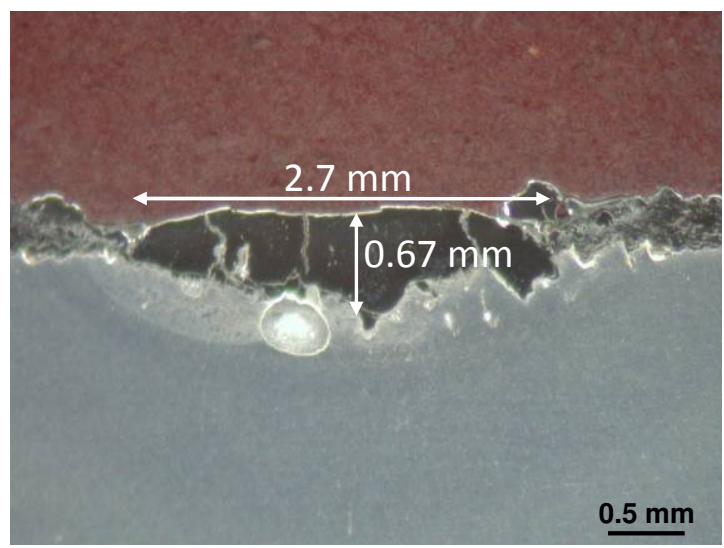

(c) Laser power: $2500 \mathrm{~W}$

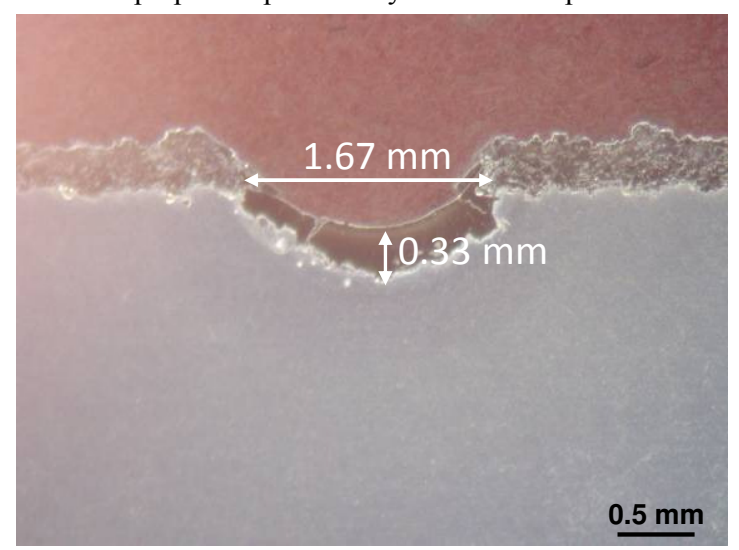

(b) Laser power: $1800 \mathrm{~W}$

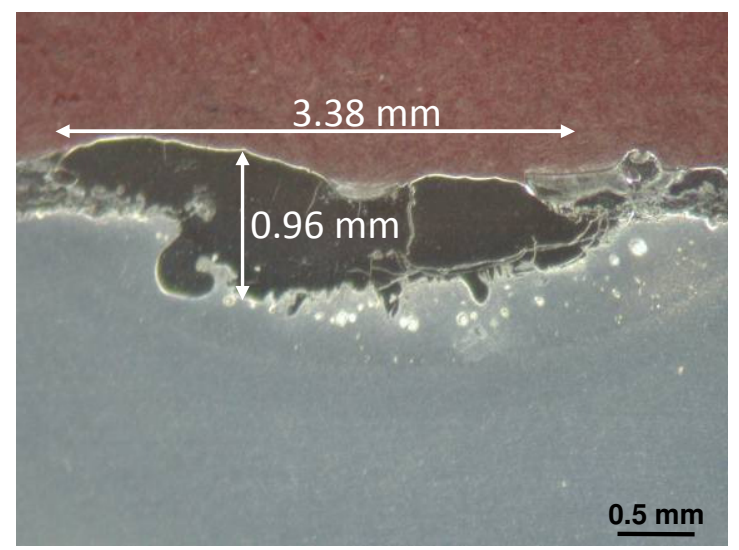

(d) Laser power: $3000 \mathrm{~W}$

Fig. (6). Effect of Nd:YAG laser power on a transverse section of solidified track after selective laser melting.

The relationship between the laser power and the track dimensions obtained from both experiments and the numerical analysis is summarized in Fig. (8). The threshold power of the Nd:YAG laser was $1800 \mathrm{~W}$ according to the experimental results and $2000 \mathrm{~W}$ according to the numerical prediction, as shown in Fig. (8a). The numerical and experimental results were sufficiently consistent. In addition, the numerical prediction of the trend in the variation of the track depth according to the laser power was highly consistent with the experimental results. By contrast, the trend in the predicted track width was less consistent with that of the experimental results. As depicted in Fig. (8b), the predicted and experimental threshold $\mathrm{CO}_{2}$ laser powers for the formation of a continuous and uniform track were $800 \mathrm{~W}$ and $600 \mathrm{~W}$, respectively. The numerical model predicted the trend in the relationship between the track depth and the laser power more accurately than it predicted the trend in the relationship between the track width and the laser power. 


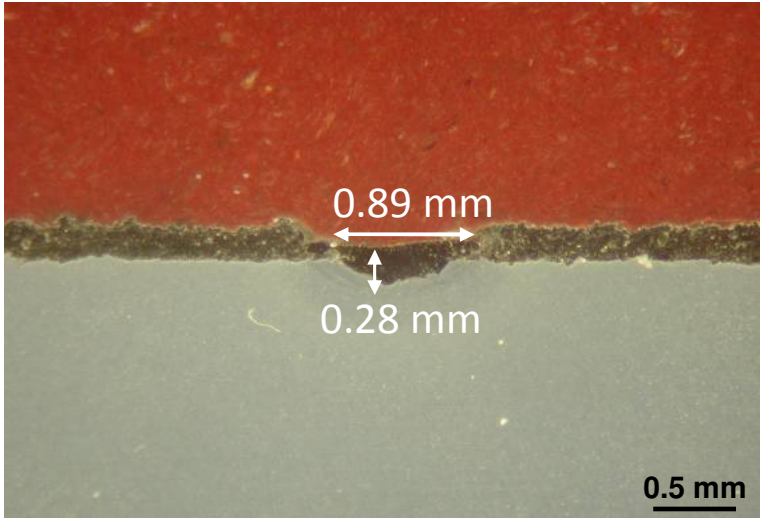

(a) Laser power: $800 \mathrm{~W}$

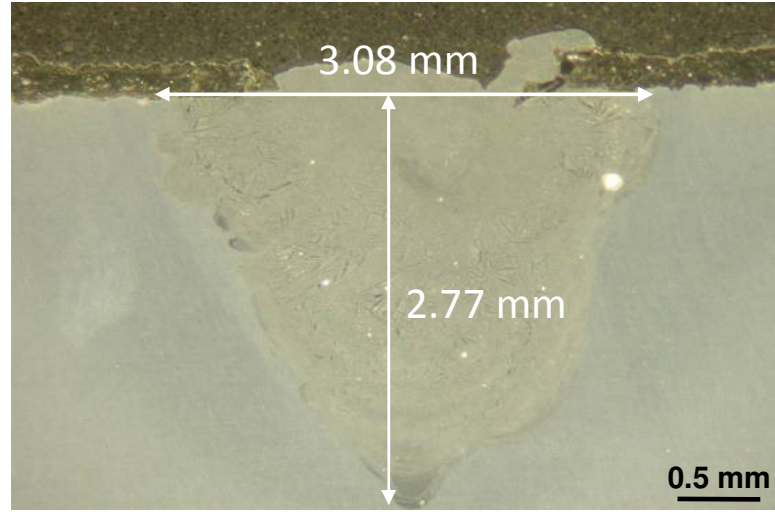

(c) Laser power: $2000 \mathrm{~W}$

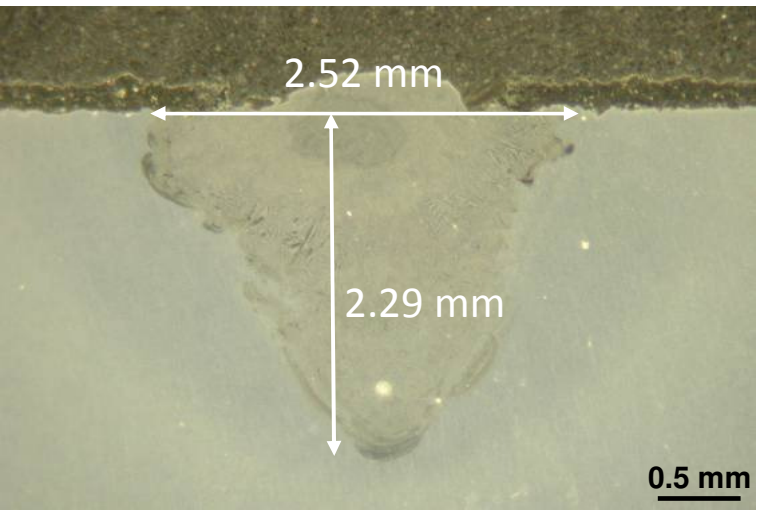

(b) Laser power: $1500 \mathrm{~W}$

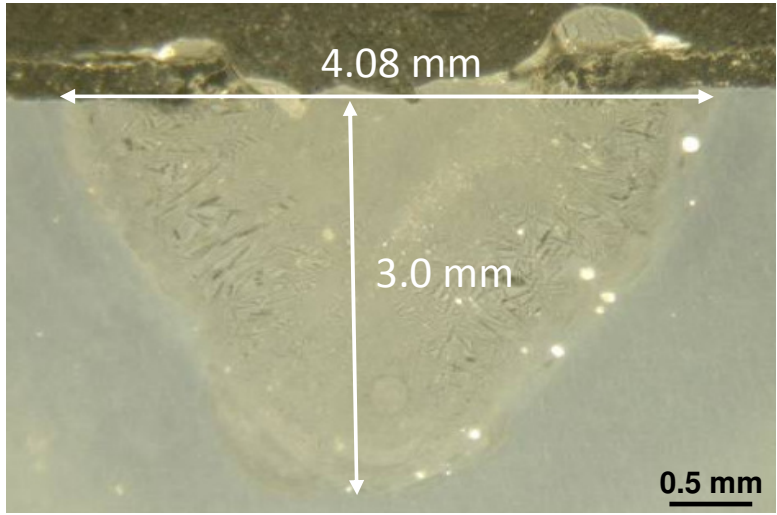

(d) Laser power: $2500 \mathrm{~W}$

Fig. (7). Effect of $\mathrm{CO}_{2}$ laser power on a transverse section of solidified track after selective laser melting.

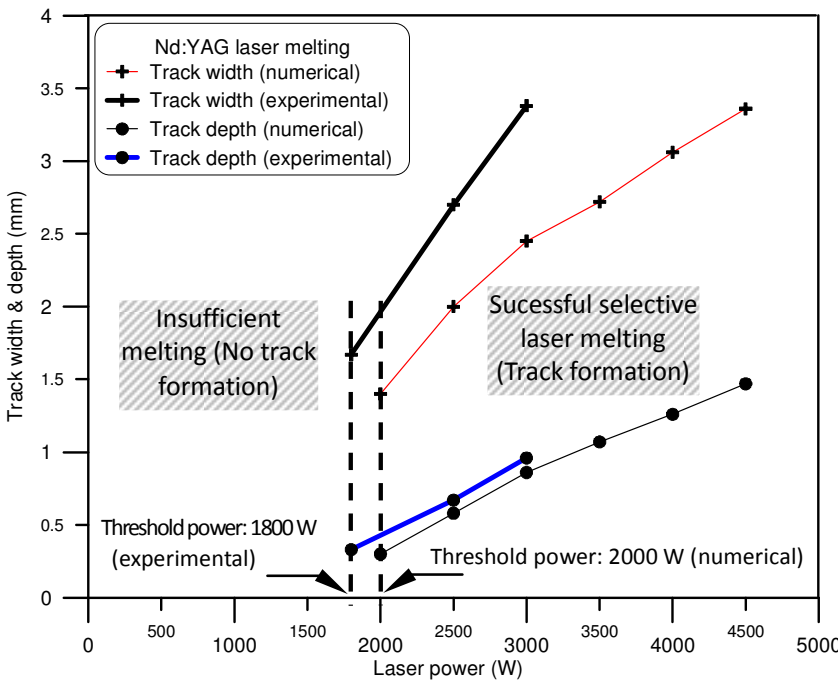

(a) $\mathrm{Nd}: Y A G$ laser

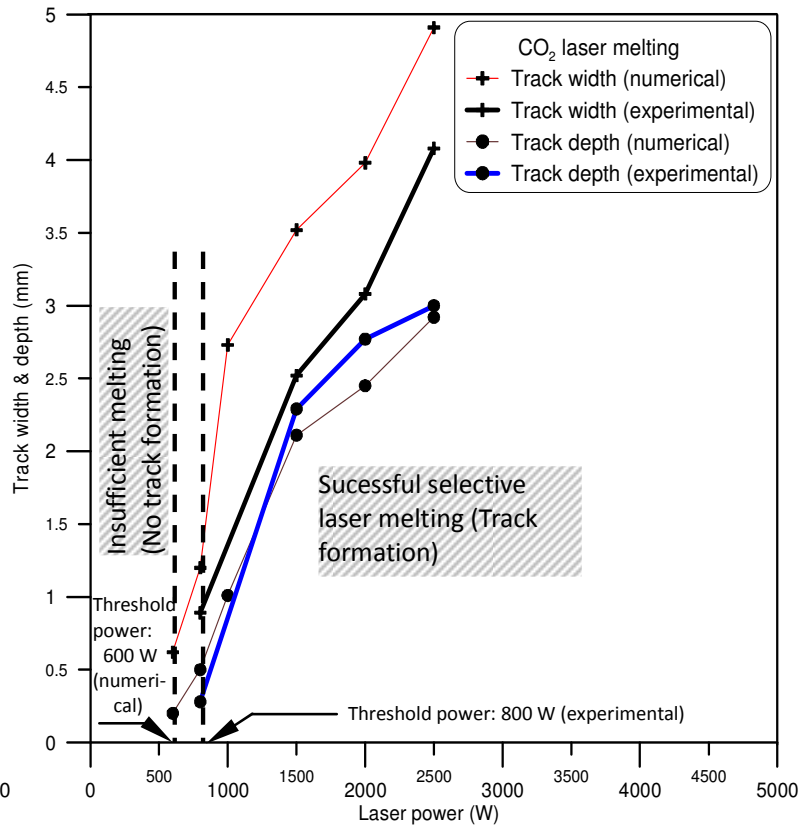

(b) $\mathrm{CO}_{2}$ laser

Fig. (8). Effect of the laser power on the solidified track dimensions. 


\subsection{Effect of the Laser Scanning Speed on the Temperature Distribution and Track Profile}

The evolution of the track profile and the temperature distribution of the melt pool at various scanning speeds when the Nd:YAG laser and the $\mathrm{CO}_{2}$ laser were applied was numerically predicted. For the Nd:YAG laser, the melt pool depth increased from $0.37 \mathrm{~mm}$ to $0.6 \mathrm{~mm}$ when the scanning speed was reduced from $400 \mathrm{~mm} / \mathrm{min}$ to $100 \mathrm{~mm} / \mathrm{min}$. The melt depth met the requirements for efficient melting deposition and low dilution of the melt pool. However, the $\mathrm{CO}_{2}$ laser formed a substantially deeper melt pool, exhibiting deviations from efficient deposition from $1.59 \mathrm{~mm}$ to 2.91 $\mathrm{mm}$. The surface morphology of the deposited track at various scanning speeds is shown in Fig. (9). The applied laser power of $2000 \mathrm{~W}$ exceeded the threshold power for both the Nd:YAG and $\mathrm{CO}_{2}$ lasers; thus, continuous and uniform solidified tracks formed in the experimental scanning speed range. The Nd:YAG-laser-deposited tracks were smooth and shiny, whereas those deposited by the $\mathrm{CO}_{2}$ laser were rippled at scanning speeds between $400 \mathrm{~mm} / \mathrm{min}$ and $200 \mathrm{~mm} / \mathrm{min}$. Applying a scanning speed of 100 $\mathrm{mm} / \mathrm{min}$ resulted in high heat input and the development of pores on the track surface.

Transverse sections of continuous tracks obtained at various scanning speeds and a laser power of $2000 \mathrm{~W}$ are shown in Figs. $(\mathbf{1 0}, \mathbf{1 1})$. The Nd:YAG laser created a wide and shallow track profile, as shown in Fig. (10). The track dimensions generally satisfied the requirements for cladding. The track width varied from $1.45 \mathrm{~mm}$ to $1.96 \mathrm{~mm}$ and the track depth varied from $0.37 \mathrm{~mm}$ to $0.77 \mathrm{~mm}$ as the scanning speed was reduced. The $\mathrm{CO}_{2}$ laser formed deep melting tracks exhibiting a triangular profile similar to the profile of a laser weld. Both the track width and depth increased as the scanning speed was reduced, as shown in Fig. (11).

Fig. (12a, b) show the relationships between the predicted and experimentally determined scanning speeds and track dimensions for the $\mathrm{Nd}: \mathrm{YAG}$ laser and $\mathrm{CO}_{2}$ laser, respectively. The experimental results validated the numerical predictions regarding the Nd:YAG laser in the selected scanning speed range. As shown in Fig. (12b), consistency between the experimental results and the results of the numerical prediction regarding the $\mathrm{CO}_{2}$ laser was greater in the trend in track depth than in the trend in the track width. Thus, the experimental investigation revealed that the employed numerical heat source model provided more accurate prediction of track dimensions for the $\mathrm{Nd}$ :YAG laser than for the $\mathrm{CO}_{2}$ laser at various scanning speeds. In general, the adequacy and usability of the tailored laser heat source were validated. As mentioned previously, the differences between SLM and laser cladding lie in the track profile dimensions and the magnitude of the required laser power. The track dimensions observed in this study ranged from $0.3 \mathrm{~mm}$ to $2 \mathrm{~mm}$, and the laser power ranged from $600 \mathrm{~W}$ to $2000 \mathrm{~W}$ when the $\mathrm{Nd}: \mathrm{YAG}$ and $\mathrm{CO}_{2}$ lasers were applied. More accurate modeling of a finer SLM process can easily be achieved by varying the power, focusing conditions, and wavelength in the tailored laser beam heat source model and by refining the mesh of the workpiece in the FEM by using the same method.

\section{CONCLUSION}

This study entailed a comprehensive experimental validation of a tailored laser heat source model used for simulating laser melting and laser cladding on a preplaced cobalt-based powder layer on a steel substrate. The effects of the beam power and scanning speed on the track profile were investigated experimentally and predicted numerically for a $\mathrm{Nd}$ :YAG laser and a $\mathrm{CO}_{2}$ laser emitting $\mathrm{TEM}_{\text {mixed }}$ mode beams. The threshold power for continuous track formation and the appropriate process parameters for laser melting were determined. The Nd:YAG laser formed a wide and shallow solidified track, whereas scanning using the $\mathrm{CO}_{2}$ laser resulted in a triangular track profile. The experimental results were generally consistent with the numerical predictions in a wide range of process parameters. The simulation tool predicted the wide and shallow track profile achieved using the Nd:YAG laser more accurately than it predicted the deep triangular track profile created by the $\mathrm{CO}_{2}$ laser. Greater consistency between the experimental and simulation results was observed in the trend in track depth variation than in the trend in track width variation as process

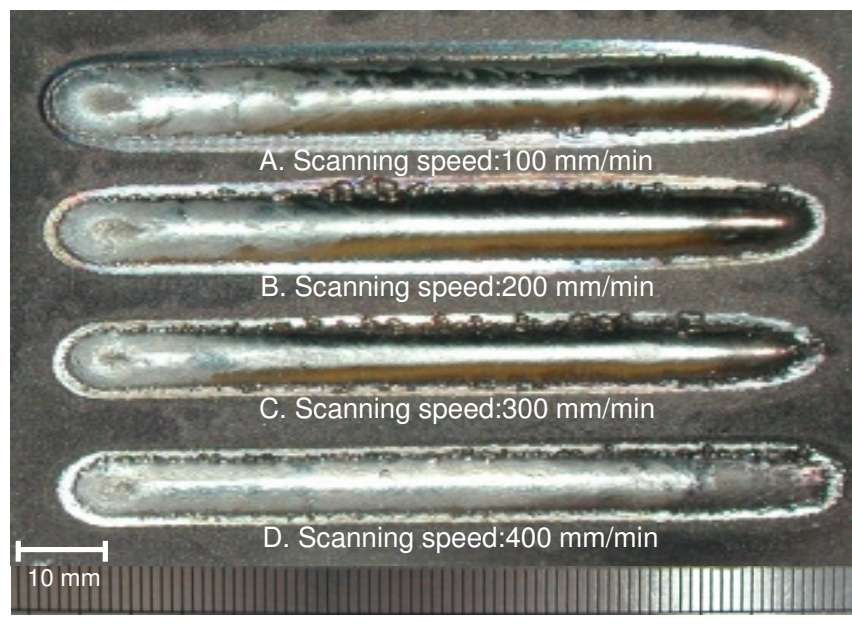

(a) Nd:YAG laser

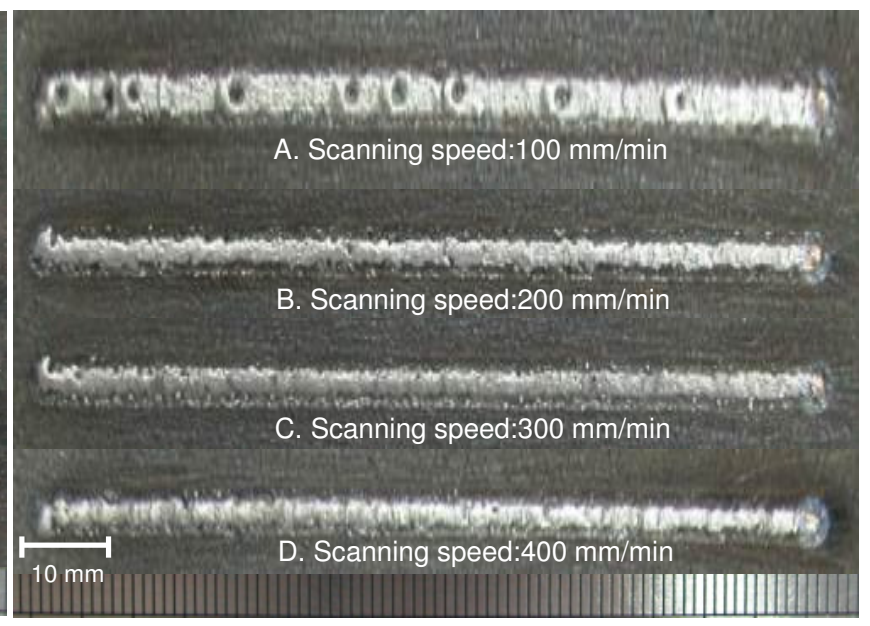

(b) $\mathrm{CO}_{2}$ laser

Fig. (9). The surface morphology of the selective melting track solidified from a preplaced powder layer at various scanning speeds. 


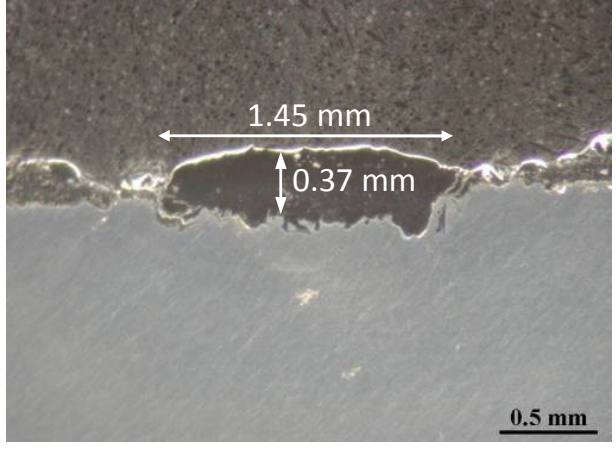

(a) Scanning speed: $400 \mathrm{~mm} / \mathrm{min}$

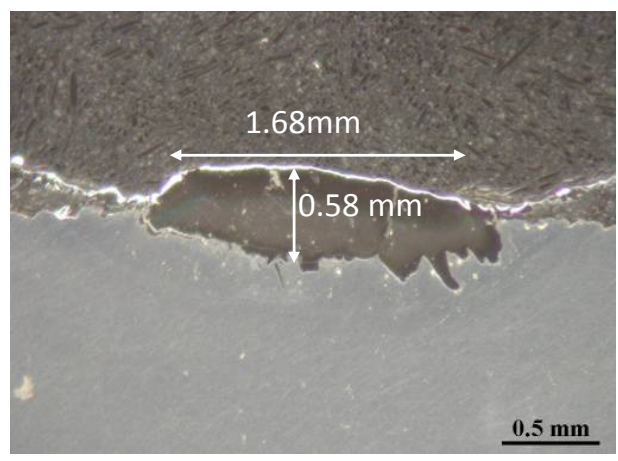

(c) Scanning speed: $200 \mathrm{~mm} / \mathrm{min}$

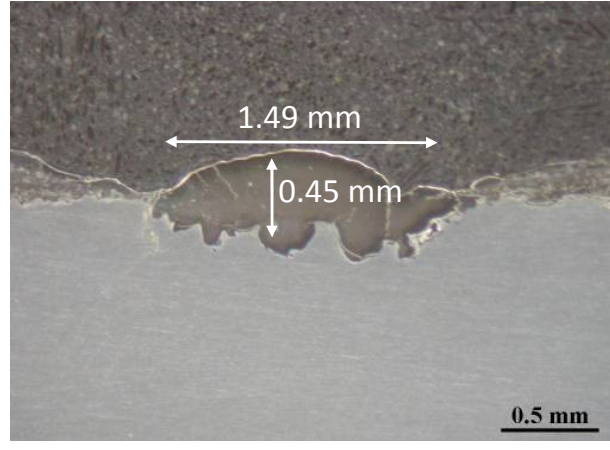

(b) Scanning speed: $300 \mathrm{~mm} / \mathrm{min}$

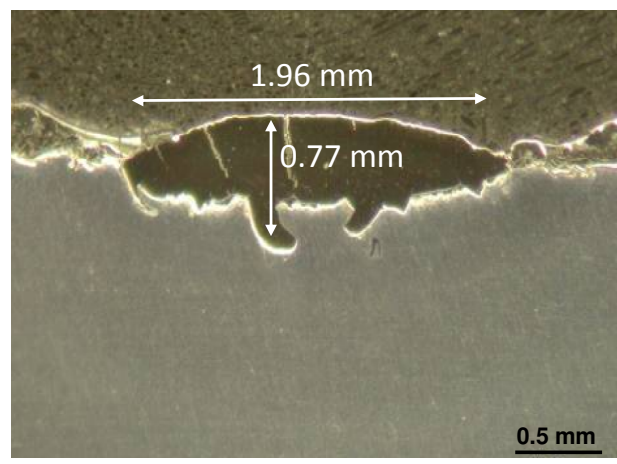

(d) Scanning speed: $100 \mathrm{~mm} / \mathrm{min}$

Fig. (10). Effect of Nd:YAG laser scanning speed on a transverse section of track after selective laser melting.

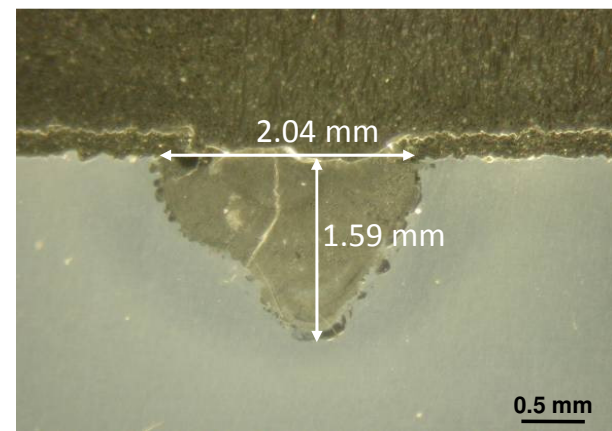

(a) Scanning speed: $400 \mathrm{~mm} / \mathrm{min}$

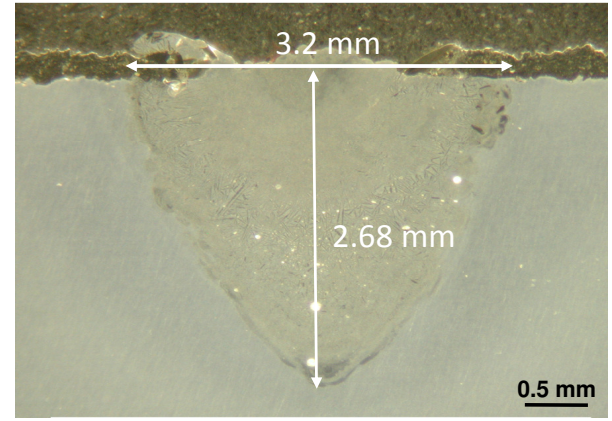

(c) Scanning speed: $200 \mathrm{~mm} / \mathrm{min}$

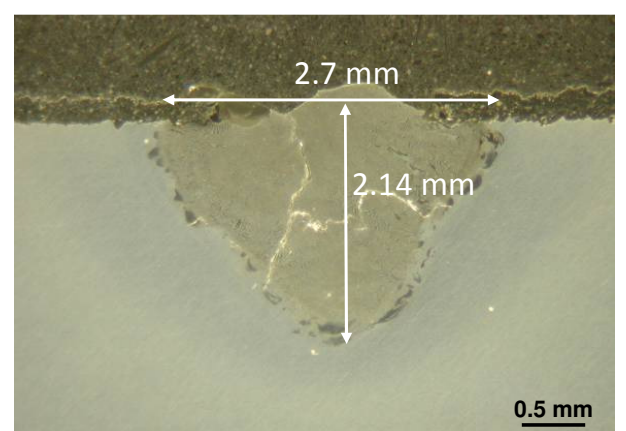

(b) Scanning speed: $300 \mathrm{~mm} / \mathrm{min}$

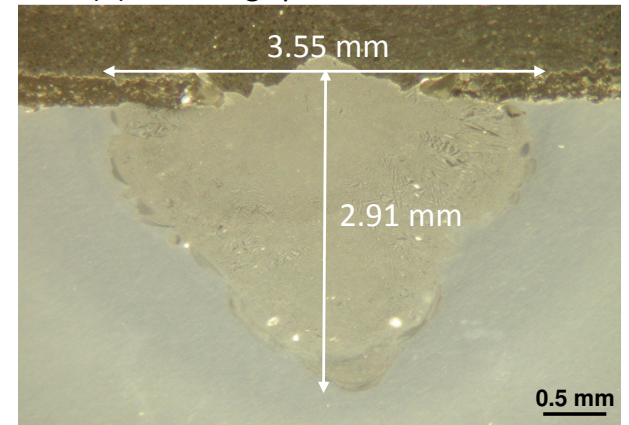

(d) Scanning speed: $100 \mathrm{~mm} / \mathrm{min}$

Fig. (11). Effect of $\mathrm{CO}_{2}$ laser scanning speed on a transverse section of track after selective laser melting.

parameters were changed. By exploring substantial process parameter variations in the laser melting experiment, the feasibility and flexibility of the tailored laser heat source model and the associated numerical model were validated.
The experimental validation and numerical model collectively provide a greater understanding of temperature evolution and track formation during the laser melting process. 


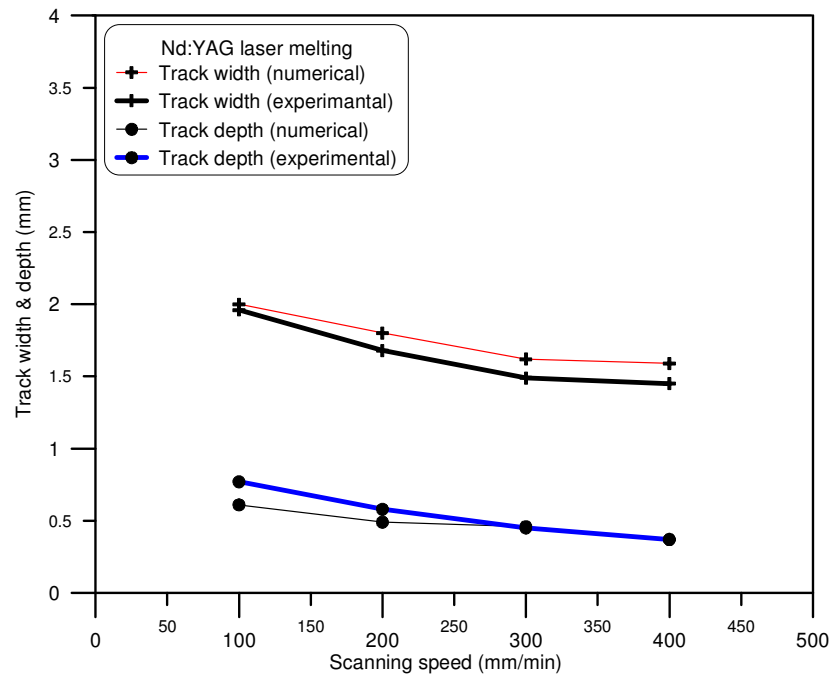

(a) Nd:YAG laser

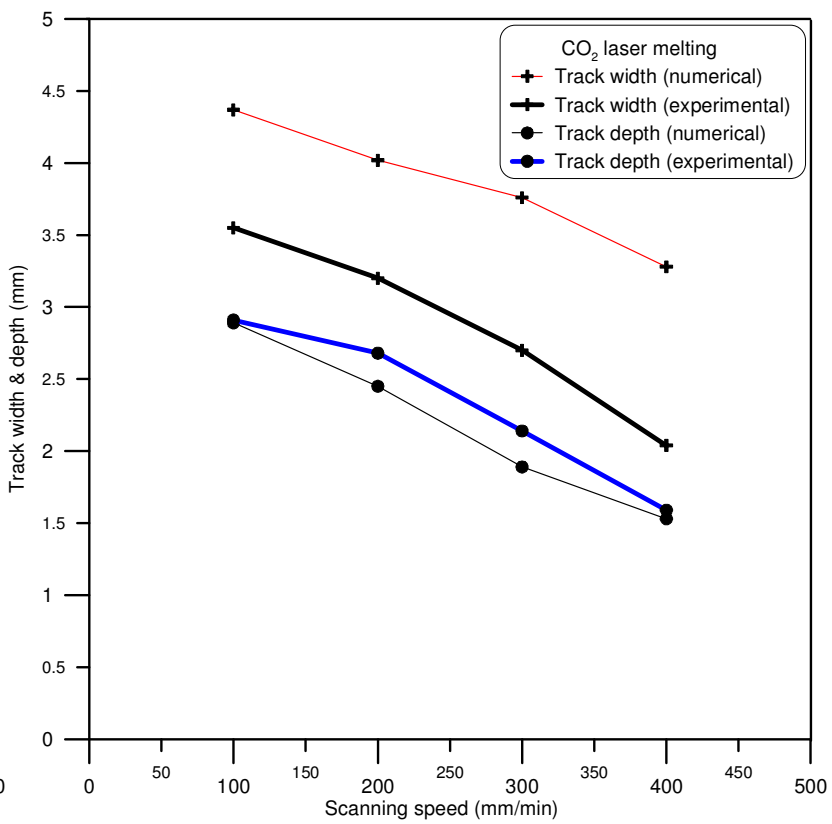

(b) $\mathrm{CO}_{2}$ laser

Fig. (12). Effect of the laser scanning speed on the solidified track dimensions.

\section{LIST OF ABBREVIATIONS}

FEM $=$ Finite element model

LAM $=$ Laser additive manufacturing

LPD $=$ Laser powder deposition

SLM = Selective laser melting

SLS $\quad=$ Selective laser sintering

TEM = Transverse electromagnetic mode

\section{Nomenclature}

A $=$ Surface area irradiated by the laser beam $\left(\mathrm{mm}^{2}\right)$

$A\left(x^{\prime}, y^{\prime}, z^{\prime}\right)=$ Initial temperature $(\mathrm{K})$

$f=$ Focal length of the lens or mirror $(\mathrm{mm})$

$H_{m}, H_{n} \quad=$ Hermite polynomials of order $\mathrm{m}$ and $\mathrm{n}$

$k=$ Temperature-dependent thermal conductivity (W/mm K)

$Q_{f} \quad=$ Laser power at the focal point $(\mathrm{W})$

$Q_{m n} \quad=\quad$ Laser power of the $\mathrm{TEM}_{m n}$ mode raw beam (W)

$Q_{w} \quad=$ Laser power on the workpiece surface (W)

$q_{f}(x, y)=$ Heat flux intensity at the focal point $\left(\mathrm{W} / \mathrm{mm}^{2}\right)$

$q_{m n}(r)=$ Heat flux intensity of a $\mathrm{TEM}_{m n}$ mode $\left(\mathrm{W} / \mathrm{mm}^{2}\right)$

$q_{w}(x, y)=$ Heat flux intensity at the workpiece surface $\left(\mathrm{W} / \mathrm{mm}^{2}\right)$

$r_{0} \quad=$ Raw laser beam radius at focusing lens $(\mathrm{mm})$

$r_{f} \quad=$ Laser spot radius at the focal point $(\mathrm{mm})$

$$
\begin{array}{lll}
r_{w} & =\begin{array}{l}
\text { Laser spot radius on the workpiece surface } \\
(\mathrm{mm})
\end{array} \\
v & =\text { Scanning speed }(\mathrm{mm} / \mathrm{min}) \\
T & =\text { Temperature }(\mathrm{K}) \\
t & =\text { Time }(\mathrm{s}) \\
x, y, z & =\text { Cartesian coordinate }(\mathrm{mm}) \\
\theta & =\text { Beam divergence angle }(\mathrm{rad}) \\
\rho & =\text { Density of the material }\left(\mathrm{kg} / \mathrm{mm}^{3}\right) \\
\alpha & =\text { Thermal diffusivity }
\end{array}
$$

\section{CONFLICT OF INTEREST}

The authors confirm that this article content has no conflict of interest.

\section{ACKNOWLEDGEMENTS}

This work was granted by the National Science Council Taiwan, ROC, under Grant Contract No. NSC 95-2218-E194-007, NSC 97-2221-E-194-024 and NSC 100-2221-E194-016-MY3. The authors thank the Metal Industry Research and Development Center (MIRDC) Kaohsiung, Taiwan for their kind provision of laser facilities.

\section{REFERENCES}

[1] A. Gasser, G. Backes, I. Kelbassa, A. Weisheit, and K. Wissenbach, "Laser additive manufacture: laser metal deposition (LMD) and selective laser melting (SLM) in turbo-engine applications", Laser Technik J., vol. 7, pp. 58-63, 2010.

[2] E.C. Santos, M. Shiomi, K. Osakada, and T. Laoui, "Rapid manufacturing of metal components by laser forming", Int. J. Mach. Tools Manuf., vol. 46, pp. 1459-1468, 2006.

[3] S. Kaierle, A. Barroi, C. Noelke, J. Hermsdorf, L. Overmeyer, and H. Haferkamp, "Review on laser deposition welding: from micro to macro", Physics Procedia, vol. 39, pp. 336-345, 2012. 
[4] I. Yadroitsev, P. Bertrand, and I. Smurov, "Parametric analysis of the selective laser melting process", Appl. Surf. Sci., vol. 253, pp. 8064-8069, 2007.

[5] A.V. Gusarov, and I. Smurov, "Modeling the interaction of laser radiation with powder bed at selective laser melting", Physics Procedia, vol. 5, pp. 381-394, 2010.

[6] C. Zhang, L. Li, and A. Deceuster, "Thermomechanical analysis of multi-bead pulsed laser powder deposition of a nickel-based superalloy", J. Mater. Process. Tech., vol. 211, pp. 1478-1487, 2011.

[7] M. Alimardani, V. Fallah, A. Khajepour, and E. Toyserkani, "The effect of localized surface preheating in laser cladding of Stellite 1", Surf. Coat. Tech., vol. 204, pp. 3911-3919, 2010.

[8] A. Fathi, E. Toyserkani, A. Khajepour, and M. Durali, "Prediction of melt pool depth and dilution in laser powder deposition", $J$. Phys. D: Appl. Phys., vol. 39, pp. 2613-2623, 2006.

[9] A. Kumar, and S. Roy, "Effect of three-dimensional melt pool convection on process characteristics during laser cladding", Сотр. Mater. Sci., vol. 46, pp. 495-506, 2009.

[10] A. Kumar, C.P. Paul, A.K. Pathak, P. Bhargava, and L.M. Kukreja, "A finer modeling approach for numerically predicting single track geometry in two dimensions during Laser Rapid Manufacturing", Opt. Laser Technol., vol. 44, pp. 555-565, 2012.

[11] C. Lalas, K. Tsirbas, K. Salonitis, and G. Chryssolouris, "An analytical model of the laser clad geometry", Int. J. Adv. Manuf. Tech., vol. 32, pp. 34-41, 2007.

[12] H. Gedda, Laser Cladding: An Experimental and Theoretical Investigation, Ph.D. dissertation, University of Lulea, 2004.

[13] P. Aggarangsi, J.L. Beuth, and D.D. Gill, "Transient changes in melt pool size in laser additive manufacturing processes", Solid Freeform Fabrication Proceedings, Proc. 2004 Solid Freeform Fabrication Symposium, Austin, TX, USA, pp. 163-174, 2004.

[14] Y. Lei, R. Sun, Y. Tang, and W. Niu, "Numerical simulation of temperature distribution and $\mathrm{TiC}$ growth kinetics for high power laser clad $\mathrm{TiC} / \mathrm{NiCrBSiC}$ composite coatings", Optic. Laser Technol., vol. 44, pp. 1141-1147, 2012.

[15] D. Hu, and R. Kovacevic, "Modeling and measuring the thermal behavior of the molten pool in closed-loop controlled laser-based additive manufacturing", J. Eng. Manuf., vol. 217, pp. 441-452, 2003.

[16] T. Chen, and Y. Zhang, "Three-dimensional modeling of selective laser sintering of two-component metal powder layers", J. Manuf. Sci. Eng., vol. 128, pp. 299-306, 2006.

[17] R.B. Patil, and V. Yadava, "Finite element analysis of temperature distribution in single metallic powder layer during metal laser sintering", Int. J. Mach. Tools Manuf., vol. 47, pp. 1069-1080, 2007.

[18] A.V. Gusarov, I. Yadroitsev, P. Bertrand, and I. Smurov, "Heat transfer modelling and stability analysis of selective laser melting", Appl. Surf. Sci., vol. 254, pp. 975-979, 2007.
[19] T.H.C. Childs, C. Hauser, and M. Badrossamay, "Selective laser sintering(melting) of stainless and tool steel powders: experiments and modelling", Proc. IMechE Part B: J. Engineering Manufacture, vol. 219, pp. 339-359, 2005

[20] S. Kolossov, E. Boillat, R. Glardon, P. Fischer, and M. Locher, "3D FE simulation for temperature evolution in the selective laser sintering process", Int. J. Mach. Tools. Manuf.", vol. 44, pp. 117123, 2004.

[21] L. Dong, A. Makradi, S. Ahzi, and Y. Remond, "Threedimensional transient finite element analysis of the selective laser sintering process", J. Mater. Process Tech., vol. 209, pp. 700-706, 2009.

[22] N. Contuzzi, S.L. Campanelli, and A.D. Ludovico, "3D finite element analysis in the selective laser melting process", Int. $J$ Numer. Modelling, vol. 10, pp. 113-121, 2011.

[23] S. Santhanakrishnan, F. Kong, and R. Kovacevic, "An experimentally based thermo-kinetic hardening model for high power direct diode laser cladding", J. Mate Process Tech., vol. 211, pp. 1247-1259, 2011.

[24] J. Goldak, A. Chakravarti, and M. Bibby, "A new finite element model for welding heat sources", Metall. Trans. B, vol. 15B, pp. 299-305, 1984.

[25] J. Ding, P. Colegrove, J. Mehnen, S. Ganguly, P.M.S. Almeida, F. Wang, and S. William, "Thermo-mechanical analysis of wire and arc additive manufacturing process on large multi-layer parts", Comp. Mater. Sci., vol. 50, pp. 3315-3322, 2011.

[26] L. Han, and F.W. Liou, "Numerical investigation of the influence of laser beam mode on melt pool", Int. J. Heat Mass Tran., vol. 47, pp. 4385-4402, 2004.

[27] S. Okano, M. Tanaka, and M. Mochizuki, "Arc physics based heat source modeling for numerical simulation of weld residual stress and distortion", Sci. Tech. Welding Joining, vol. 16, pp. 209-214, 2011.

[28] J. N. Aoh, and S. J. Liao. "Numerical analysis and experimental validation on laser cladding process with preplaced powder layer", Mathematical Modeling of Weld Phenomena 8, Verlag der Technischen Universität Graz, Austria, 2007, pp. 455-468.

[29] W. C. Tseng, and J. N. Aoh, "Simulation study on laser cladding on preplaced powder layer with a tailored laser heat source", Opt. Laser Technol., vol. 48, pp. 141-152, 2013.

[30] H.C. Man, K.H. Leong, and K.L. Ho, "Process monitoring of powder pre-paste laser surface alloying", Opt. Laser Eng., vol. 46, pp. 739-745, 2008

[31] R. Li, J. Liu, Y. Shi, L. Wang, and W. Jiang, "Balling behavior of stainless steel and nickel powder during selective laser melting process", Int. J. Adv. Manual Technol., vol. 59, pp. 1025-1035, 2012.

[32] I. Yadroitsev, A. Gusarov, I. Yadroitsava, and I. Smurov, "Single track formation in selective laser melting of metal powders", $J$. Mater. Process. Tech., vol. 210, pp. 1624-1631, 2010.

[33] D. Radaj, "Heat Effect of Welding," Springer-Verlag, pp. 33, 1992.

Received: June 7, 2014

Revised: July 8, 2014

Accepted: July 8, 2014

(C) Tseng and Aoh; Licensee Bentham Open.

This is an open access article licensed under the terms of the Creative Commons Attribution Non-Commercial License (http://creativecommons.org/licenses/ by-nc/3.0/) which permits unrestricted, non-commercial use, distribution and reproduction in any medium, provided the work is properly cited. 